\title{
The Effectiveness of Return to Community Program On Increasing Interpersonal Skills and Life Quality of Patients with Schizophrenia
}

\author{
Morteza Gazani Zad ${ }^{1}$, Omid Moradi ${ }^{2}$ \\ ${ }^{1}$ MSc of Clinical psychology, Islamic Azad University of Sanandaj, Sanandaj, Iran. \\ ${ }^{2}$ Professor of Psychology Department, Islamic Azad University of Sanandaj, Sanandaj, Iran.
}

\begin{tabular}{ll} 
ARTICLE INFO & ABSTRACT \\
\cline { 2 - 2 } $\begin{array}{l}\text { Keywords: } \\
\text { Return to community } \\
\text { program, interpersonal } \\
\text { skills, life quality, }\end{array}$ & $\begin{array}{l}\text { This study aims to evaluate the effectiveness of return to community } \\
\text { program on increasing interpersonal skills and life quality of patients }\end{array}$ \\
schizophrenia & purpose and is semi-experimental with two groups of control and \\
& experiment in terms of implementation method. For this purpose, \\
& among the patients with schizophrenia in Sanandaj, 24 patients were \\
& selected by available sampling method and divided into two groups \\
& of 12 patients. At first, both groups responded to questionnaires of \\
& increased interpersonal skills and life quality. Then, for the first \\
& group of experiment, 16 sessions of return to community based \\
& educational program were conducted in a group, but no intervention \\
& was performed for the control group. After intervention, the data \\
& obtained from questionnaires of interpersonal skills and life quality \\
from patients of two groups were used in the pre-test and post-test & phases using MANCOVA statistical method for measuring the \\
& significance level and then analyzed. The results showed that return \\
& to community program had a significant effect on increasing \\
interpersonal skills and life quality in patients with schizophrenia \\
(0.05).
\end{tabular}

\section{Introduction}

Schizophrenia is a major mental disorder that causes disorders in the emotional, cognitive and social spheres, and thus, leads to losing abilities in adapting to environmental changes and proper performance in community (Haller \& Kumar Mahatou, 2015). Schizophrenia is a clinical comprising the psychological injuries but deeply devastating that involves cognition, excitement, perception, and other aspects of behavior (Kaplan \& Sadock, 2013, translated by Rezaei, 2014). Because this disorder influences on person's perception of reality and deeply disturbs it and since it has a premature onset and chronic duration, this disorder has become the most disabling psychiatric disorder (Kaplan \& Sadock, 1393). Schizophrenia affects many aspects of a person's life. One of these important aspects is to lose social skills and interpersonal relationships. Patients with schizophrenia have problem in finding friend and maintaining interpersonal relationships, they do not have the necessary skills to live independently and, in

* Corresponding Author E-Mail Address: safoorakhoshde191@yahoo.com 
worst cases, lose their jobs due to lack of social skills (Nangal, Hanson and Ardely and Norton, 2010). One of the important variables that greatly affects the lives of patients with schizophrenia is life quality. Life quality has a multidimensional and complex concept because it considers both objective and mental factors (Seva, Ribaccus, and Ligilat-Radzoikin, 2013). Factors, such as life standard, health status, mental and physical ability, income, education, property, knowledge, social relationships and security refer to the objective dimension of life quality (Netuveli \& Blane, 2008). Some researchers believe that in assessing the life quality, only objective criteria should be used; they do not consider the mental experiences of a person as valuable or trustworthy concepts. (Bond, 2006, translated by Mohagheghi Kamal, 2010). Training on returning to community skills is another variable that is relevant to the life of patients with schizophrenia. Therefore, one of the important supporting approaches to improve the life quality of people with schizophrenia is to train skills to return to the community. Generally, these skills are referred to as abilities that a person uses to communicate with others and return to community. These skills are based on the social norms of each community and determine which behaviors are considered acceptable in each community and in each particular situation, what behavior is expected from the individual. Moreover, because of the characteristics of the return to community program that is implemented in a group, it seems patients are encouraged to do things, respond to questions, doing in-class duties and complete different work sheets by working together and helping each other; therefore, the spirit of collaboration among patients is reinforced (Patrick, 2008). The results of studies show the effectiveness of this therapeutic model on patients with schizophrenia for returning to community (Nangal, Hanson, Ardeli and Norton, 2010; Weisman, 2005; Shahmiri, Talebizadeh and Jafarifard, 2014; Hojjati Abed, Karbalaei Noori, Rafiei and Karimlou, 2014). Skills training and return to community program are the approaches that are specifically designed to improve the social skills of people with schizophrenia. Interventions of this approach are intended to face the patient to real life situations and daily problems. This model consists of instructional instructions, division of skills into smaller sections, modeling and behavioral exercises, role play and social reinforcements. Individuals usually learn several skills individually and then learn how to combine them (Mueser and Jeste, 2008).

Creating deep cultural changes and lifestyle changes have made many people lack of basic ability to face with challenges and problems of life and this has made them vulnerable to face with daily problems (Valizadeh, 2002). Regarding the role and importance of mental health of people in health system of the country, it is essential to conduct interventional and empirical researches with aim of incorporating psychological educational programs. Therefore, the aim of this paper is to examine the effectiveness of return to community education program on increasing interpersonal skills and life quality in patients with schizophrenic. Therefore, considering the above-mentioned items, this paper attempts to respond this question that whether return to community training has an impact on increasing interpersonal skills and the life quality of patients with schizophrenia.

Yogin Bloler (1991) first applied the term schizophrenia which means the breakdown and separation of brain (Kaplan and Sadock, 1387). This disorder is characterized by positive symptoms, such as hallucination and thinking disorder, and negative symptoms, such as social performance disorder and lack of targeted behavior. An important point that must be considered by clinicians is that the diagnosis of schizophrenia is based entirely on psychiatric memoir and 
examination of psychological state. There is no experimental testing method for diagnosis of schizophrenia (Kaplan \& Sadock, 2013; translated by Rezaei, 2014). Now, based on knowledge of Psychiatric, etiology of schizophrenia is affected by multi factor meaning that schizophrenia may be exacerbated as result of environmental disorder, mental stress or physical illness in individual that is genetically predisposed to this disease (Foroughan, 2005).

Disorder in daily performance of schizophrenic patients have been studied in several studies. Aein et al. (2009) by investigating 82 schizophrenic patients found that performance capability of such patients have been limited and have an impact on overall performance and independent social life. Goodbout et al. (2007) in a study on 33 schizophrenic patients showed the disorder of staging and timing in performing life daily activities. One of the major injuries of schizophrenia is inability in establishing the interpersonal relationships. It is difficult for many people with schizophrenia to transmit a topic to others. They try hard to explain the content to others, but the result is just frustration for patients. Sometimes, writing the content helps the patient. Some schizophrenic patients may be astounding, responding to no question, or staring into the sky. It should be noted that these are not due to insolence or obstinacy (Thornton, 2005). Shahmir, Talebizadeh and Jafarifard (2014) concluded that implementation of return to community program is effective on promoting the social skills of patients with schizophrenia. Hojjati Abed, Karbalaei Nouri, Rafiei and Karimloo (2014) presented that the term "life skills" is said to a large group of psychosocial, social and interpersonal skills that can help individuals make their decisions consciously, communicate effectively, expand their coping and personal management skills and have a healthy and fertile life. Program of life skills' training in 1993 was formulated by the World Health Organization to prevent the mental diseases and increase the level of mental health of the community. The organization (1993) introduced ten main skills as life skills and put them into five groups:

1. Self-awareness-empathy (emphasizing on self-esteem and self-confidence enhancement skills);

2. Communication - Interpersonal relationships (with emphasis on interpersonal skills and selfexpression)

3. Decision making - Problem solving

4. Creative thinking - Critical thinking

5. Restraining emotions and dealing with stress

In fact, interpersonal skills are the necessary skills of a person to communicate effectively with someone else or a group. There is a tendency to agree on core areas that are necessary for more effective interpersonal interactions. These include: self-awareness, effective listening, asking, oral communication, helping or facilitating, reflection and feedback, courage, and non-verbal communication. A number of communication activities, including non-verbal behaviors and the ability to detect and describe messages follow from non-verbal communication that is also considered as central interpersonal skills (Harigan, Rosental and Scherr, 2005).

Although there is no general agreement on definition of life quality (Fernandez et al., 2012), most researchers agree on the life quality features. These features are: Being mental, dynamism and being multi-dimensional (Kharazmi, 2010; Hajira and Aboud, 2013).

A) being mental: Life quality should be used in the form of a mental concept. An individual's assessment of health and well-being is a key factor in the study of life quality. A person's judgment on illness, disability, treatment and health is more important than an objective 
assessment of health. For example, someone may suffer from one or more dimensions of chronic illness but consider himself to be healthy, while another person in spite of having no more objective indication of illness consider himself to be ill (Kharazmi, 2010). The main determinant factor of life quality is the perceived difference between what is exists and what should be in view of individual.

B) Dynamism: Life quality has a dynamic and fluid nature, not a static one. That is, it is a timedependent process and is influenced by personal experience and one's perception of life. The dynamic nature of life quality suggests that the life quality varies over time and depends on changes in the person and his environment. This characteristic can be observed in a longitudinal relationship (Kharazmi, 2010).

C) Being multi-dimensional: Life quality is a multi-dimensional concept and is based on dimensions that are closely related to each other, therefore, it is necessary to be measured from different angles and dimensions. These dimensions include physical dimension, psychological dimension, social dimension, mental dimension, and then symptoms associated with the disease or treatment-related changes (Kharazmi, 2010).

In fact, health is important in our understanding of life quality, because for many people, illness or disability is an obstacle to access and is a major factor in their material and psychological dependence. Many people, after physical disability cannot live in the community and perform their social functions. Therefore, this situation poses some limitations in one's life and can confront him with loneliness and social isolation (Van der Slot et al., 2010; Band, 2006; Translated by Mohagheghi Kamal, 2010).

\section{Method}

The present research is applied in terms of the purpose and is semi-experimental of pre-test and post-test type with control group in terms of implementation method. The aim of this study was to investigate the effectiveness of return to community education program on increasing interpersonal skills and life quality in patients with schizophrenia in both experimental and control groups. The statistical population of this study comprises all adult schizophrenic males and females under medical treatment in hospitals and clinics in Sanandaj in the first half of 1396. Using available sampling method, 24 patients who were diagnosed schizophrenic by interview and implementation of SCID_I test and were willing to cooperate were selected and divided into two experimental and control groups and training was applied to the experimental group.

The research tools consisted of three standard questionnaires:

Structured clinical interview for Axis I disorders in DSM_IV: In the Assessment of main psychiatric disorders, SCID_I is a measured comprehensive tool designed for use in clinical and research purposes. The implementation of this tool requires clinical judgment of the interviewer about the responses of interviewee, therefore, the interviewer must have sufficient knowledge and experience in the field of psychological pathology. The validity and reliability of this tool have been reported in various acceptable studies. In the study, Huff Kappai reported the diagnosis validity more than $0.7 \%$. The Persian version of this questionnaire was developed and validated by Sharifi et al. (2004), and a desirable validity and reliability was reported. In this study, the reliability of the questionnaire was 0.84 . 
Interpersonal Relationship Questionnaire: The Standard Questionnaire of Interpersonal Problems Assessment (IIP-32) is derived from the questionnaire of Barkham et al. (1994). This questionnaire has 32 questions and includes 6 components of frankness and publicity, openness, considering others, aggression, supporting, participation and affiliation and measures the interpersonal relationships. Its response range is Likert that was calculated in the research of Monjemizadeh (2012) for the simultaneous validity of the questionnaire and a strong correlation was obtained between it and questionnaire of ability to effectively communicate $(r=0.896)$, therefore, its simultaneous validity was confirmed. Reliability of the questionnaire was calculated using Cronbach's alpha. Cronbach's alpha for interpersonal communication skills questionnaire was obtained 0.73 which indicates a good reliability of this questionnaire.

Life quality Scale: The questionnaire contains 36 questions with multiple-choice answers and measures individual's viewpoint to health (Nejat, 2008). Translation and determination of reliability and validity of Persian version of SF-36 questionnaire conducted by Montazeri, Goshtasbi, Vahdani Nia (2005) in Tehran in people aged 15 and more years. Their studies have necessary adequacy of this means to use in Iranian community. The SF-36 scale has eight dimensions of physical function, physical role, physical pain, general health, vitality, social performance, emotional role, and mental health, that their reported alpha coefficients are 0.90 , $0.85,0.71,0.65,0.77,0.84$ and 0.77 , indicating a good internal consistency of these dimensions.

\section{Findings}

In this research, in order to respond the questions, the inferential statistics and multivariate analysis were used to analyze the collected data. Before analyzing the research data, the underlying assumptions of analysis were studied. The most important of these assumptions is the assumption of being normal. Kolmogorff-Smirnov test (K-S) was used to evaluate the assumption of normal distribution of the data. The Kolmogorov-Smirnov test was calculated for all variables, with the results as follows:

Table 1: The Results of normal testing of the research variables

\begin{tabular}{|c|c|c|c|c|c|}
\hline \multicolumn{3}{|c|}{ Variables } & $\mathrm{N}$ & Significance level & Error value \\
\hline $\begin{array}{c}\text { Interpersonal } \\
\text { skills (IIP) }\end{array}$ & Pre-test & Test & 12 & 0.943 & 0.5 \\
\cline { 3 - 6 } $\begin{array}{c}\text { Life quality } \\
\text { (SF) }\end{array}$ & \multirow{2}{*}{ Pre-test } & Control & 12 & 0.579 & 0.5 \\
\cline { 3 - 6 } & & Test & 12 & 0.697 & 0.5 \\
\cline { 3 - 6 } & Control & 12 & 0.616 & 0.5 \\
\hline
\end{tabular}

As the table shows, Kolmogorov-Smirnov test values for interpersonal skills (IIP) and life quality (SF) variables in pre-test in the experimental group were 0/528 and 0/709, respectively, while Kolmogorov-Smirnov test values for interpersonal skills (IIP) and life quality (SF) variables in pre-test in the control group were $0.756,0.779$, respectively that the significance level of each of the variables in two groups of pre-test exceeds the error value (0.05). Therefore, it can be said that the distribution of data is normal in two groups.

Question 1: Does education of return to community program have an impact on improving the interpersonal skills (IIP) of schizophrenic patients? 
The results of covariance analysis and multivariate variance analysis of the data were analyzed. The results of the statistical presumptions showed that considering the precondition for equality of variances (using Levine test) and insignificant amount of $\mathrm{F}$ at the error level of smaller than 0.05 in the interpersonal skills (IIP) subscale variable, the error variance of this variable varies in the education of the return to community program. Also, considering the value of $F=1.935$ and the greater significance level of the box test than 0.05 , it can be said that the post-test homogeneity assumption of the test has been realized. Since it is necessary to observe the homogeneity condition of the regression slopes and variance equality, multivariate analysis (MANCOVA) was used to analyze the data of this hypothesis. The results are reported in the table below.

Table 2: The results of multivariate test for assessing the significance of the effect of each independent variable

\begin{tabular}{|l|l|c|c|c|c|c|c|}
\hline Variable & Test name & Value & $\begin{array}{c}\text { F- } \\
\text { statistic }\end{array}$ & $\begin{array}{c}\text { DF } \\
\text { Hypothesis }\end{array}$ & $\begin{array}{c}\text { DF } \\
\text { Error }\end{array}$ & $\begin{array}{c}\text { Significance } \\
\text { Level }\end{array}$ & $\begin{array}{c}\text { Eta } \\
\text { Square }\end{array}$ \\
\hline \multirow{2}{*}{ Group } & Pillai effect & 0.75 & 8.01 & 5.00 & 13.00 & 0.001 & 0.755 \\
\cline { 2 - 8 } & Lambedai wilkz & 0.24 & 8.01 & 5.00 & 13.00 & 0.001 & 0.755 \\
\hline
\end{tabular}

Multivariate tests were used to examine the effects of independent variables. Result of this test in the above table showed that the value of Lambadai Wilkes' test is equal to 0.24, which considering the relevance of Lambadai Wilkes' test with the probability ratio criterion, it can be said that the F-test value of the Lambda test is significant at an error level of less than 0.05. That is, the variable subscales (interpersonal skills (IIP)) play a role in the model altogether and have a significant effect on return to community education $(\mathrm{p}=0.001)$.

Table 3: The normalized average of the groups in the interpersonal skills (IIP)

\begin{tabular}{|c|l|l|c|c|}
\hline Variable & & Group & Average & Standard Deviation \\
\hline \multirow{5}{*}{$\begin{array}{l}\text { Interpersonal } \\
\text { skills (IIP) }\end{array}$} & \multirow{2}{*}{ Frankness } & Test & 24.98 & 0.639 \\
\cline { 2 - 5 } & \multirow{2}{*}{ Openness } & Control & 22.68 & 0.639 \\
\cline { 2 - 5 } & \multirow{2}{*}{ Considering others } & Test & 9.29 & 0.745 \\
\cline { 2 - 5 } & \multirow{2}{*}{ Aggression } & Control & 11.53 & 0.745 \\
\cline { 2 - 5 } & & Cest & 12.57 & 0.513 \\
\cline { 2 - 5 } & \multirow{2}{*}{ Support } & Control & 14.83 & 0.513 \\
\cline { 3 - 5 } & & Cest & 10.71 & 0.453 \\
\cline { 3 - 5 } & & Control & 12.70 & 0.453 \\
\cline { 2 - 5 } & & Test & 10.90 & 0.483 \\
\cline { 2 - 5 } & Control & 13.09 & 0.483 \\
\hline
\end{tabular}

In the above table, we observe the normalized averages of the subscales post-test of interpersonal skills (IIP). The effect of auxiliary random variables is statistically eliminated. Averages indicate that the average of experimental group is lower than the control one. They also shows that there is a significant difference between the experimental group that was under the training and the control group that was not under any training and this difference is in the interest of the trained group due to the normalized averages. Therefore, it is concluded that return to community program has an impact on increasing the interpersonal skills (IIP).

Second question: Does education of the return to community program have effect on life quality (SF) of schizophrenic patients? 
The results of covariance analysis and multivariate variance analysis of the data were analyzed. The results of the statistical presumptions showed that considering the precondition for equality of variances (using Levine test) and insignificant amount of $\mathrm{F}$ at the error level of smaller than 0.05 in life quality (SF) subscales variable, the error variance of this variable varies in the education of the return to community program, as well as the period return to community program that has effect on increasing the life quality are equal and there is difference between them. Also, considering the value of $\mathrm{F}=1.25$ and the greater significance level of the box test than 0.05 , it can be said that the post-test homogeneity assumption of the test has been realized. Since it is necessary to observe the homogeneity condition of the regression slopes and variance equality, multivariate analysis (MANCOVA) was used to analyze the data of this hypothesis. The results are reported in the table below.

Table 4: The results of multivariate test for assessing the significance of the effect of each independent variable

\begin{tabular}{|l|l|c|c|c|c|c|c|}
\hline Variable & Test name & Value & F-statistic & $\begin{array}{c}\text { DF } \\
\text { Hypothesis }\end{array}$ & $\begin{array}{c}\text { DF } \\
\text { Error }\end{array}$ & $\begin{array}{c}\text { Significance } \\
\text { Level }\end{array}$ & $\begin{array}{c}\text { Eta } \\
\text { Square }\end{array}$ \\
\hline \multirow{2}{*}{ Group } & Pillai effect & 0.84 & 4.90 & 8.00 & 7.00 & 0.025 & 0.849 \\
\cline { 2 - 8 } & Lambadai wilkz & 0.15 & 4.90 & 8.00 & 7.00 & 0.025 & 0.849 \\
\hline
\end{tabular}

Multivariate tests were used to examine the effects of independent variables. Result of this test in the above table showed that the value of Lambadai Wilkes' test is equal to 0.15 , which considering the relevance of Lambadai Wilkes' test with the probability ratio criterion, it can be said that the F-test value of the Lambda test is significant at an error level of less than 0.05. That is, the variable subscales (life quality (SF)) play a role in the model altogether and have a significant effect on return to community education $(\mathrm{p}=0.025)$.

As shown in Table 5, there is a significant difference between two groups of experiment and control groups after normalizing the pre-test scores of the variables subscales of life quality (SF). Therefore, the zero assumption that was based on the lack of difference between two groups is rejected.

Table 5: Normalized average of groups in life quality (SF)

\begin{tabular}{|c|c|c|c|c|}
\hline \multirow{16}{*}{ Life quality } & \multirow{2}{*}{ Pain $(\mathrm{P})$} & Control & 03-Febrayer & 0.15 \\
\hline & & Test & 2.30 & 0.15 \\
\hline & \multirow{2}{*}{ Pain (P) } & Control & 3.51 & 0.25 \\
\hline & & Test & 2.54 & 0.25 \\
\hline & \multirow{2}{*}{ Emotional Welfare (EW) } & Control & 2.50 & 0.16 \\
\hline & & Test & 3.26 & 0.16 \\
\hline & \multirow{2}{*}{ Emotional Welfare (EW) } & Control & 3.46 & 0.24 \\
\hline & & Test & 2.30 & 0.24 \\
\hline & \multirow{2}{*}{ Emotional Disorders (RE) } & Control & 2.90 & 0.20 \\
\hline & & Test & 03-October & 0.20 \\
\hline & \multirow{2}{*}{ Emotional Disorders (RE) } & Control & 3.91 & 0.21 \\
\hline & & Test & 2.92 & 0.21 \\
\hline & \multirow{2}{*}{ Physical Disorders (PF) } & Control & 2.95 & 0.13 \\
\hline & & Test & 3.48 & 0.13 \\
\hline & \multirow{2}{*}{ Physical Function (PF) } & Control & 2.39 & 0.14 \\
\hline & & Test & 03-Febrayer & 0.14 \\
\hline
\end{tabular}


In the above table, we observe the normalized averages of the subscales post-test of life quality $(\mathrm{SF})$. The effect of auxiliary random variables is statistically eliminated. Averages indicate that the average of experimental group is lower than the control one. They also shows that there is a significant difference between the experimental group that was under the training and the control group that was not under any training and this difference is in the interest of the trained group due to the normalized averages. Therefore, it is concluded that return to community program has an impact on increasing the life quality (SF).

\section{Discussion and Conclusion}

Return to community program includes some educations about drugs and increasing the drug compliance, to communicate effectively with others, especially physicians, to train social roles, to feedback to members of the group after playing each role, training related to issues in the community, training on community-accepted activities such as right spending the leisure time, training on avoiding antisocial behavior, such as alcohol and drugs consumption, training on stress management in social situations, and training on how to request help from the others, especially when observing alarming symptoms. Therefore, in connection with the first question of the research that:

Does training on return to community program have an impact on increasing the interpersonal skills of schizophrenic patients?

The results of data analysis indicated that training on return to community program has been effective in increasing the skills of schizophrenic patients. This finding is consistent with the results of Xiang and Wang (2007), Xu et.al (1999), Smith et al. (1998) and Kopelowicz et.al (1998), Moghtadaei et al. (2011), Sharifi et al. (2013), Farisabadi et al. (2015).

In analyzing this question, it can be said that schizophrenia affects many aspects of a person's life. One of these important aspects is to lose the social skills and interpersonal relationships. They resist being discharged and are not interested in discharging (Golman, 1965). Except for negligible connections with hospital staff and small phone calls and small visits, schizophrenic patients in centers and hospitals have no connection with the outside world (Lieberman and Silbert, 2005). They have problem in finding friends and maintaining interpersonal relationships, they do not have the necessary skills to live independently, and in more severe cases, they lose their jobs because of lack of social skills (Nangel, Hanson and Ardelly and Norton, 2010). Xiang and Wang (2007), in a study titled "the effectiveness of return to community program on schizophrenic patients in China" showed that training of return to community program increases social functions, decreases psychological symptoms, increases insight and reduces relapse and readmission. Also, these findings are consistent. Shahmir and et al. (1393) in their research concluded that implementation of this program is effective on promoting social skills of schizophrenic patients. This program learn patients that when observing alarming symptoms of the occurrence of a disease course or even when its relapse use its ability to request help from the others. They learn that they cannot lonely recognize the signs of illness relapse, and they must help a healthy person to recognize these symptoms and in order to recognize these symptoms timely and discuss with their physician. In this program, patients learn to communicate effectively with others by performing multiple roles. In this program, patients are able to regularly practice their learned social skills by placing themselves 
in different roles, such as the role of the patient, the role of the physician, or even role of normal and healthy people.

Life quality is an important part of public health. Disturbed life quality is one of the causes and also effect of psychiatric illnesses and is an important factor in assessing the consequences of various therapeutic approaches. Studying the different dimensions of life quality in these patients in different aspects, such as follow-up of treatment response, patient's rehab and patient's and family's compliance with the disease can be effective in planning for treatment and services, can be applied in rehabilitation and ultimately preventing from relapse of disorder, maintaining and improving the mental health of his family. In various studies, life quality of schizophrenic patients has been reported to be lower than the general population (Forouzandeh et al., 2011). Therefore, in connection with the second question, the research suggests that:

Does the training of return to community program affect the life quality of patients with schizophrenia?

The results of this study showed that training of return to community program has been effective on increasing the life quality of patients with schizophrenia. These results are consistent with the results of the studies by Solanki et al. (2010), Duval (2010), Cardoso et al. (2005), Foruzandeh et al. (2011), Navid et al. (1988). In analyzing this question, it can be said that due to the limited resources of many families in preserving patients, some of them are deposited in the care centers, and some are released wanderer and defenseless in community due to lack of organized cares. Many of patients become unemployed and isolated, 20-50 percent of patients suicide that 9-13 percent of them end up with death (Kaplan and Sadock, 2005). Therefore, recent studies focus on improving the life quality of these patients. Because life quality is one of the important criteria determining the effects of schizophrenia and its treatment on individual (Cardoso et al., 2005) and can be a useful guide to improve the care quality (Carlson et al., 2000). Therefore, evaluation of patient care and clinical research is important. Duval (2010) argues that no one, even a professional person, can determine the life quality of patients, and contrary to the general belief, even severely ill patients can determine the most important factors affecting their life quality.

Negative symptoms in schizophrenia are the most disturbing symptoms of patients with schizophrenia. Accordingly, it can be said that because negative signs cause poverty and social isolation and disconnection of the patient's interpersonal relationship with the world around him and can lead to decreasing the life quality of these patients (Navid, Abolghasemi and Narimani, 2009). In the end, it is suggested that further researches are conducted on the educational-psychological interventions of families considering the state of mental patients and use of other therapeutic methods in relation to these individuals, educational workshops are created and family psychosocial education in clinical settings and psychiatric hospitals are implemented. Considering the role of non-pharmacological treatments in improving or exacerbating illness, education of patients and families on communication skills and stress management and problem solving seem necessary. It is also suggested that the role of nonpharmacological and community-based interventions in comparison to drug therapies in role and function are investigated in the future researches.

\section{References}


Benvanente, A., Morales, B., Rubio., E., A., Rey, T., M. (2004). Quality of life in adolescents suffering from epilepsy living in the community, JPCH, 40(3): 110-113.

Bond, John. (2006). Life quality and the elderly, (translated by Hossein Mohagheghi Kamal, 2010), Tehran: Danjeh.

Brown, R., L., Turner, R., J. (2010). Physical disability and depression: clarifying racial/ethnic contrasts, Journal of Aging and health, 22(7): 977-1000.

Browne S, Clarke M, Gervin M, Waddington JL, Larkin C, O'Callaghan E. (2000). Determinants of life quality at first presentation with schizophrenia. Br J Psychiatry; 176: 173-6.

Cardoso SC, Caiaffa TW, Bandeira M, et al. (2005). Factors associated with low life quality in schizophrenia. Rio de Janerio: Saude Press: 1338-1348.

Chan S, Yu IW. (2003). Life quality of clients with schizophrenia. JAN; 45(1): 72-83.

Chein,W.T.,\&Wong K.F. (2007).Afamily Psycho Education Programe for Chinese family carer of members with Schizophrenia .Life quality research,15,719_724.

Csernansky,G.J. (2002).Maintainnance Treatment for Schizophrenia In:Schizophrenia:a new Guide for Clinicians,Marcel Dekker ,Newyork.

Diagnostic and statistical manual of psychiatric disorders based on DSM-V (2013). The author of American Psychiatric Association; translated by Farzin Rezaei et al. (1393). Tehran: Arjomand.

Duval HM. (2010). Life quality and severe and persistent mental illness: A pilot study [dissertation]. New England: Antioch University.

Edelman,R.J.(2000).Psycho social Aspect of the Health care Process .New York:Education.

Faris Abadi, Leila, Khosravi, Masoumeh and Sabahi, Parviz (2015). The Effectiveness of interpersonal communication skills training and social problem solving on improving adaptive behavior and academic performance of mental-disable female students. Journal of Special individuals, Fifth Year, Number 1. Pages: 101-118.

Fernandeze-Ballesteros, R., Arias-Merion, E., Santacreu, M., Mendoza, N. (2012). Life quality in Mexico and in Spain. International perspectives on aging and social wellfare: A global anahysis. New York, NY: Nova.

Foruzandeh, Nasrin; Delaram, Masoumeh; Ayein, Fereshteh and Daris, Fatemeh (2011). Investigating the relationship between positive and negative symptoms with life quality of chronic schizophrenic patients admitted to Sina Hospital of Joungan. Journal of Behavioral Sciences Researches. Volume (9), Issue (4). Pages 295-306.

Frisch, M.B. (2006). Finding happiness with Life quality Therapy: Appositive psychology approach. Wood way, TX : Life quality Press.

Goldman,H.H.(1984). The chronically mentally ill:Who are they?Where are they? In M.Mirabi (Ed), Research and services (pp.33-44):Spectrum Publications.

Gottesman, I., \& Shields, J. (1982). Schizophrenia: The epigeneticpuzzle. Cambridge: Cambridge University Press. Gove, W. R., \& Tudor, J. (1973). Adult sex roles and mentalllness. American Journal of Sociology, 77, 812-835.

Halder, Susmita; Kumar Mahato; Akash (2015). Cognitive Impairment in Schizophrenia: An Overview of Assessment and Management, The International Journal of Indian Psychology, Volume 2, Issue 4, 64-72. 
Hojjati Abed, Elaheh; Karbala'i Noori, Ashraf; Rafiee; Hasan; Karimloo Massoud (2014). The Impact of psychosocial therapy on life quality of patients with chronic psychiatric disorders. Research Paper of Research Journal. Volume 11 (1): 0-0.

Kaplan HJ \& Sadock BJ. (2003) Synopsis psychiatry, Behavioral Sciences/Clinical psychiatry. 9thed. Baltimore: Williams and Wikins.2005;658-699.

Kennedy, P., Evans, M., Sanhu, N. (2009). Psycholocal adjustment to spinal ccord injury: the contribution of coping, hope and cognitive appraisals. Psychology health and medicin, 14(1): 17-33.

Kharazmi, Shahindoukh. (2010). Life quality and indicators of happiness, Tehran: Haft Tabligh [In Persian].

Kopelowicz, A., Liberman, R.P., \& Zarete, R. (2006). Recent advances in social training for schizophrenia. Schizophrenia Bulletin, 32, 12-23.

Liberman, R.P., \& Silbert, K. (2005). Community re-entry: Development of life skills. Psychiatry, 68 (3), 220-229.

Liberman, R.P., Silbert, K. (2005). Community re-entry: Development of life skills. Psychiatry, 68 (3), 220-229.

Millon, T., Blancey, P.H.;Davis, R.D.(1999)- Schizophrenia -in :Oxford Text book of Psychopathology- Oxford Unibersity Press .pp:277-311.

Moqhtadaee, Mansour; Amiri; Sholeh; Molavi, Hussein; and Azad, Nasim. (2011). The effectiveness of Social Skills Training Program on behaviors of victim boy children in primary school of Isfahan. Social Psychology Researches, Volume 1, Issue 2, Pages 123139.

Mueser, K. T., \& Jeste, D.V. (Eds.). (2008). Clinical handbook of schizophrenia. New York: Guilfred Press.

Nangle, D. W., Hansen, D.J., Erdley, C., \& Norton, P.J. (2010). Practitioner's guide to empirically based measures of social skills. New York: Springer.

Navid S, Abolghasemi A, Narimani M. (2009). The relationship of emotional responses and positive and negative symptoms with life quality in schi zophrenic patients. Journal of Guilan University of Medical Sciences; 18 (71): 64-71. [In Persian].

Nejat, Saharnaz, Montazeri, Ali, Halakouei Naeini, Kourosh, Mohammad, Kazem., Majedzadeh, Reza, A. (2006). Standardization of life quality questionnaire of World Health Organization (translation and psychometry of Iranian person, Journal of Health faculty and hygienic research institution. Vol 4, No 4, pages: 1-12.

Netuveli, G., Blane, D. (2008). Life quality in order ages. British Medical bulletin, 85(1): 113126.

Partick, N.J. (2008). Social skills for teenagers and adults with asperger syndrome. London and Philadelphia:Jessica Kingsley Publishers.

Philips, D. 2012, Life quality: concept, policy and practice: Routledge.

Purafkari, Nosrat-allah. (1994). Comprehensive dictionary of psychology-psychiatry, contemporary culture. Volume II: 1340.

Sadock, Benjamin, James., Virginia, Alcout (2007). Summary of Psychiatry in behavioral sciences and clinical psychiatry (Translated by Farzin Rezaee). Tehran: Arjomand.

Saroukhani, Bagher (2015). Sociology of communications. Publisher: Etela'at. 
Shahmir, Elmira, Talebizadeh, Meghdad, Jafari Fard, Soleiman (2014). The Effectiveness of return to community program on promoting the social skills of schizophrenic patients. Journal of thoughts and behavior. Eighth Edition, No. 31.

Smith, T. E., Hull, J. W., MacKain, S. J., \& et al. (1996). Training hospitalized patients with schizophrenia in community reintegration skills. Psychiatric Services, 47, 1099- 1103.

Solanki RK, Singh P, Midha A, et al. (2010). Disability and life quality in schizophrenia and obsessive compulsive disorder: A cross-sectional comparative study. East Asian Arch Psychiatry; 20: 7-13.

Thornton, J.F., Seenan, M.V., \& Plummer, E.D. (2005). How do we cope with side effects of drugs in schizophrenia late? The exceptional parent. Eur Journal devpsychol, 37(5): 78-82.

WeismanAG. (2005).Intergrating culturally based approaches with existing intervention for IIispanic /Latino families coping with Schizophrenia.Isychother Res prac. ، 42:178-97.

WHO Life Quality Group. (1994). WHOQOL-BREF Introduction, Adminstration and scoring, Field Trial version, World Health Organization. Geneva.

WHO. (2001). Mental Health View Understanding: New Hope. WHO, 100-103.

Williams, J. B. (1988). A structured interview guide for the Hamilton Depression Scale.Archives of General Psychiatry, 45, 742-747.

Xiang, Y., Weng, Y.z., \& et al. (2007). Efficacy of the community re-entry module for patients with schizophrenia in Beijing, China: Outcome at 2 years follow up. The British Journal of Psychiatry, 190, 49-56.

Zhang H, Wisniewski SR, Bauer MS. (2006). Comparison of perceived life quality across clinical states in bipolar disorder: Data from first 2000 Systematic Treatment Enhancement Program For bipolar Disorder (STEP-BD) participants. ComprPsychiatry; 47: 161. 